\title{
CORRESPONDENCE OPEN Cannabinoids drive Th17 cell differentiation in patients with rheumatic autoimmune diseases
}

\author{
Konstantin Kotschenreuther $\mathbb{1}^{1}$, Iris Waqué', Shuaifeng Yan ${ }^{1}$, Anja Meyer ${ }^{1}$, Thom Haak ${ }^{1}$, Julia von Tresckow ${ }^{2}$, Joanna Schiller ${ }^{2}$, \\ Lydia Gloyer ${ }^{1}$, Mara Dittrich-Salamon ${ }^{1}$ and David M. Kofler $\mathbb{B}^{1,2}$
}

Cellular \& Molecular Immunology (2021) 18:764-766; https://doi.org/10.1038/s41423-020-0437-4

The legalization of cannabinoids for medical use has reinforced their emerging role as a treatment of chronic pain in patients with cancer or rheumatic diseases. ${ }^{1,2}$ In addition to their role as pain relievers, evidence obtained from animal models suggests that cannabinoids have immunosuppressive properties. ${ }^{3}$ However, a definite immunosuppressive function of cannabinoids has not yet been confirmed in clinical trials. ${ }^{4}$ We therefore analyzed the influence of the cannabis derivative cannabidiol (CBD) and the endogenous cannabinoid anandamide (AEA) on T helper type 17 (Th17) cells from patients with rheumatoid arthritis (RA), systemic lupus erythematosus (SLE), and psoriatic arthritis (PsA). Interestingly, in vitro culture in the presence of CBD significantly increased Th17 cell differentiation in CD4+ T cells from the peripheral blood of patients with RA, SLE, or PsA, while Th17 cell differentiation was suppressed in healthy individuals (Fig. 1a and Supplementary Fig. S1A). In RA patients, the median Th17 cell frequency in CBD-treated cells was $6.54 \pm 0.52$ vs. $3.27 \pm 0.23$ in the vehicle control group $(p<0.0001)$, and in healthy controls, the frequency was $1.86 \pm 0.25$ in CBD-treated cells vs. $3.62 \pm 0.32$ in the vehicle control group $(p=0.0002)$. AEA showed similar effects on CD4+ T cells from patients but did not affect CD4+ T cells from healthy controls (Fig. 1a). The addition of the Th17 skewing cytokines transforming growth factor- $\beta$, interleukin (IL)-1 $\beta$, IL-6, and IL-23 further increased the Th17-inducing properties of CBD (Fig. 1b). As shown previously in experimental autoimmune encephalomyelitis (EAE) mice, the production of interferon- $\gamma$ and tumor necrosis factor-a was reduced in the presence of CBD in patients with rheumatic diseases, as well as in healthy individuals (Supplementary Fig. S1B, C). During our study, some of our RA patients reported the use or planned use of $C B D$ oil as a pain reliever. In these cases, we compared Th17 cell frequencies before and after treatment initialization and found that treatment with CBD oil for 4-8 weeks drove Th17 cell expansion in vivo (1.10 \pm 0.32 before vs. $4.52 \pm 1.34$ after CBD treatment; Fig. 1c). Interestingly, disease activity measured by Disease Activity Score 28-joint count $C$ reactive protein significantly increased during CBD treatment (Fig. 1d). In accordance with previous reports, this immunomodulatory effect of $C B D$ was not mediated by the receptors CB1, CB2, or GPR55 (Supplementary Fig. S2A). ${ }^{5}$ To further assess the characteristics of the CBD-induced Th17 cells, we analyzed their gene expression profiles and discovered a CBDmediated increase in SGK1 expression (Fig. 1e, Supplementary Fig. S2C). This is remarkable, as SGK1 is an important regulator of the reciprocal development of proinflammatory Th17 cells. ${ }^{6}$ In addition, the expression of CSF2 was decreased and the expression of $A H R$ was increased by CBD (Fig. 1f $-\mathrm{g}$ and Supplementary Fig. S2B, C).

Th17 cells play a central role in the pathogenesis of PsA and ankylosing spondylitis. In addition, they have been linked at least partly to the pathogenesis of various other rheumatic autoimmune diseases. We observed an increase in Th17 cell frequencies induced by $C B D$ in vitro, as well as in some patients with $\mathrm{RA}$ receiving $C B D$ treatment. These results are in contrast to observations made in mice with $E A E$, in which cannabinoids ameliorated disease activity. ${ }^{3}$ However, CB2-selective agonists are often used in these animal studies. ${ }^{3}$ The CB2 receptor is known to mediate immunosuppressive effects, while immuneactivating effects have been attributed to other receptors. ${ }^{3}$ We used cannabinoids that activate various receptors and pathways. Variations in these receptors and pathways between patients with rheumatic autoimmune diseases and healthy individuals could explain differences between patients and healthy subjects. Moreover, the variety of $C B D$ receptors could be responsible for the discrepancy between animal studies and findings in humans, including our study. In conclusion, our data show that cannabinoids increase Th17 cell frequencies and suggest that they may therefore be used with caution in patients with rheumatic autoimmune diseases.

\section{ACKNOWLEDGEMENTS}

This work was supported by a grant from the Fritz Thyssen Foundation (10.17.2.019MN to D.M.K.), by the Köln Fortune Program of the Faculty of Medicine of the University of Cologne (to L.G. and D.M.K.), and by the foundation "Exzellenz initiieren" - Stiftung Kölner Krebsforschung (to D.M.K.). A.M. was supported by a fellowship from the German Federal Ministry of Education and Research (BMBF): Professorinnenprogramm II, Förderung der Regelprofessur im Fach Archäoinformatik (01FP14039G, Projekt-No. 4600/8116/01).

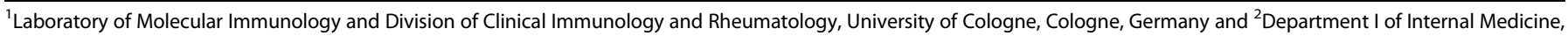
University of Cologne, Cologne, Germany

Correspondence: David M. Kofler (david.kofler@uk-koeln.de)
}

Received: 28 March 2020 Accepted: 31 March 2020

Published online: 28 April 2020 
A $\mathrm{HC}$

RA

SLE

PsA
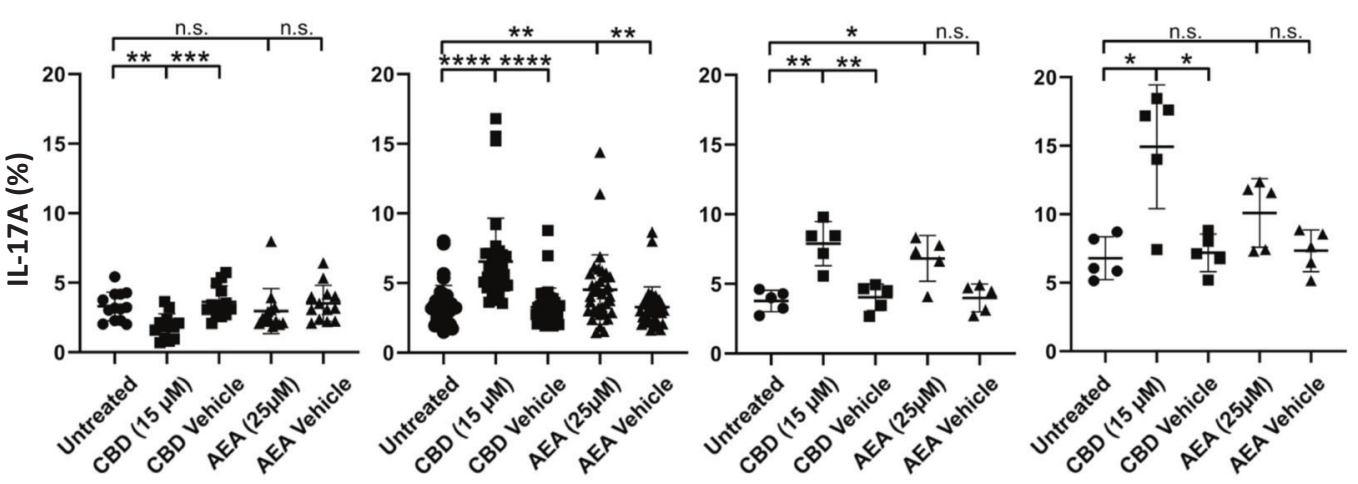

B

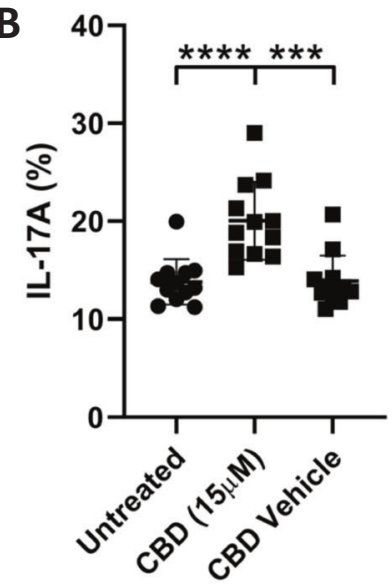

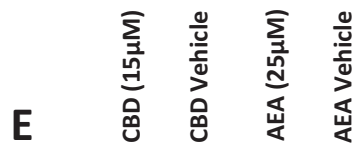
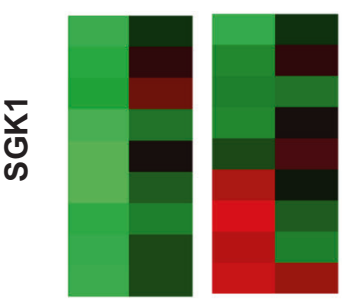

C
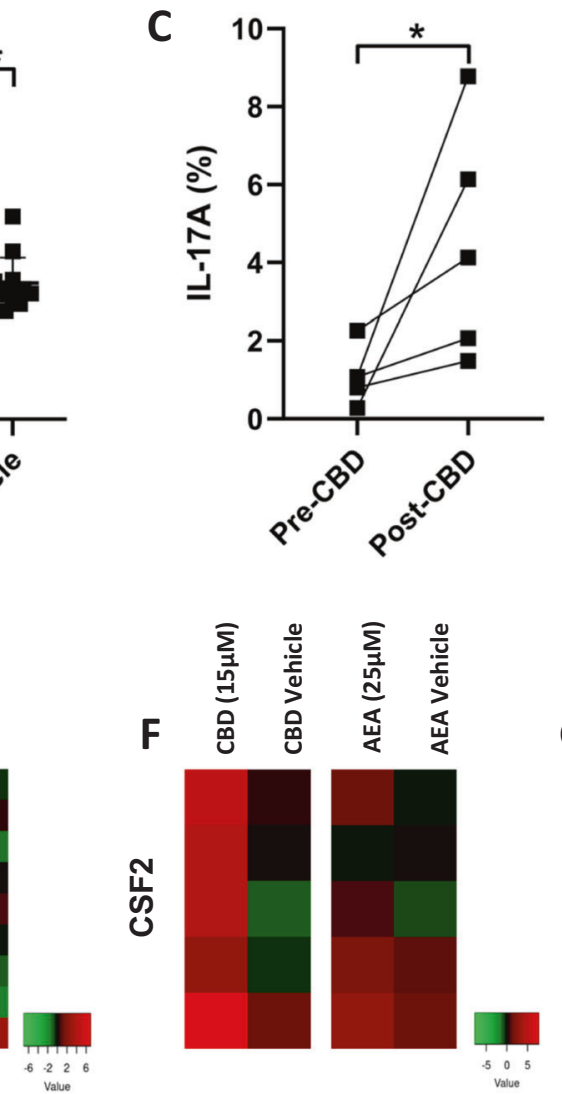

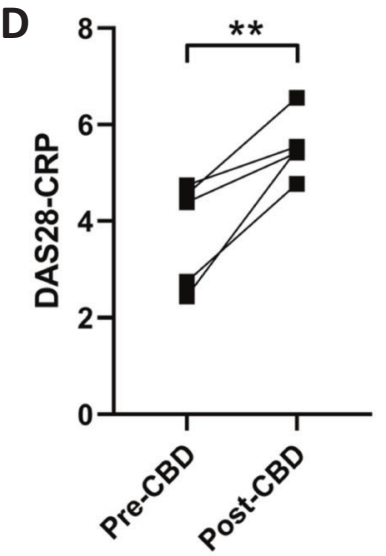

Fig. 1 Cannabinoids induce Th17 cell differentiation in patients with rheumatic diseases. a Expression of IL-17A in CD4+ T cells from healthy controls and patients was analyzed by flow cytometry (HC, $n=13 ; \mathrm{RA}, n=36$; SLE, $n=5, \mathrm{PsA}, n=5)$. b CBD-mediated induction of IL-17A expression in CD4+ T cells from RA patients in the presence of TGF $\beta$, IL-1 $\beta$, IL-6, and IL-23 $(n=12)$. c Increase in IL-17A-positive Th17 cells in patients receiving cannabidiol oil for 4-8 weeks $(n=5)$. d DAS28-CRP in patients receiving cannabidiol oil for $4-8$ weeks $(n=5)$. e-g Heat maps showing gene expression in RA patients treated with CBD or AEA. Gene expression was analyzed by RT-PCR. ${ }^{*} p<0.05,{ }^{* *} p<0.01,{ }^{* * *} p<0.001,{ }^{* * * *} p<0.0001$; the data are presented as the mean \pm SEM; significant differences were determined using the unpaired Mann-Whitney test and Student's $t$ test

\section{AUTHOR CONTRIBUTIONS}

K.K., I.W., S.Y., A.M., and D.M.K. made substantial contributions to the study concept and design. K.K., I.W., S.Y., A.M., T.H., J.v.T., J.S., L.G., and M.D.-S. made substantial contributions to the acquisition of the data. All authors drafted the article or revised it critically for important intellectual content, reviewed the draft, and approved the submission of the manuscript. Open access funding provided by Projekt DEAL.

\section{ADDITIONAL INFORMATION}

The online version of this article (https://doi.org/10.1038/s41423-020-0437-4) contains supplementary material.
Competing interests: The authors declare no competing interests.

Ethics approval: This study was approved by the Ethics Committee of the University Hospital Cologne (no. 13-091).

\section{REFERENCES}

1. Caulley, L., Caplan, B. \& Ross, M. Medical marijuana for chronic pain. N. Engl. J. Med. 379, 1575-1577 (2018). 
Cannabinoids drive Th17 cell differentiation in patients with rheumatic... $\mathrm{K}$ Kotschenreuther et al.

766

2. Blake, D. R., Robson, P., Ho, M., Jubb, R. W. \& McCabe, C. S. Preliminary assessment of the efficacy, tolerability and safety of a cannabis-based medicine (Sativex) in the treatment of pain caused by rheumatic arthritis. Rheumatology (Oxford) 45, 50-52 (2006).

3. Kong, W., Li, H., Tuma, R. F. \& Ganea, D. Selective CB2 receptor activation ameliorates EAE by reducing Th17 differentiation and immune cell accumulation in the CNS. Cell Immunol. 287, 1-17 (2014).

4. Katz-Talmor, D., Katz, I., Porat-Katz, B. S. \& Shoenfeld, Y. Cannabinoids for the treatment of rheumatic diseases - where do we stand? Nat. Rev. Rheumatol. 14, 488-498 (2018).

5. Kozela, E. et al. Cannabinoids decrease the Th17 inflammatory autoimmune phenotype. J. Neuroimmune Pharmacol. 8, 1265-1276 (2013).

6. Wu, C. et al. SGK1 governs the reciprocal development of Th17 and regulatory T cells. Cell Rep. 22, 653-665 (2018).
Open Access This article is licensed under a Creative Commons Attribution 4.0 International License, which permits use, sharing, adaptation, distribution and reproduction in any medium or format, as long as you give appropriate credit to the original author(s) and the source, provide a link to the Creative Commons license, and indicate if changes were made. The images or other third party material in this article are included in the article's Creative Commons license, unless indicated otherwise in a credit line to the material. If material is not included in the article's Creative Commons license and your intended use is not permitted by statutory regulation or exceeds the permitted use, you will need to obtain permission directly from the copyright holder. To view a copy of this license, visit http://creativecommons. org/licenses/by/4.0/.

(c) The Author(s) 2020 